\title{
Development of Information Technologies, Planned Obsolescence and Modification of the Life-Cycle of the CAD/CAM/CAE Systems
}

\author{
Galin Milchev ${ }^{1}, \mathrm{PhD}$, Radoslav Miltchev ${ }^{2}, \mathrm{PhD}$
}

\begin{abstract}
Contemporary production is impossible without the contemporary tools for its automatisation. The development of information technologies has created prerequisites for an alteration of the industrial paradigm from mass production towards individualised production. The rapid advancement and continuous improvement of technology are the reason why computer software as well as many other intangible assets, among which are the CAD/CAM/CAE systems, to be highly susceptible to technological obsolescence. Determining the duration of their useful life depends on the opportunities for the onset of risk events that lower the length of the time period in which they generate revenue for the business enterprise.

The object of study in this article are the processes of physical, moral and planned obsolescence of the basic component of computer-aided productions, namely machines with digitally programmed control, as it is one of the main directions of realising the reindustrialisation processes. Examined are both the main trends in the development of that part of assets of corporations, and the changes in their life-cycle. On the basis of research and comparative methods, an assessment is made of the opportunities for eliciting maximum benefits for small and medium-sized enterprises by achieving a synergic effect between the processes of moral obsolescence, the development of information and communication technologies, reindustrialisation and the formation of the economy structure on both a national and a global level. With that it is possible for a reversive process to be achieved, of transforming the capital costs for tangible and intangible assets into operating costs.
\end{abstract}

Key words: planned obsolescence, life-cycle, information technologies, CAD/CAM/CAE.

\section{Introduction}

The development of ICT in recent years has a decisive impact on the radical changes in all spheres of the globalized society's economy and particularly on those taking place in the industry. The ICTs themselves are not an absolute monolithic sector of the economy, but are an alloy of three strands: hardware, communications and software which develop in both a distinct and a close relationship. This also applies to their related industries where two main areas are formed: the creation of tangible products, such as computer-communication elements, forming the material part of corporations' long-term assets, and the development of software that essentially creates elements of intangible fixed assets.

The exceptional dynamics in the development of both fields, which are inextricably linked raises a number of problems corresponding with both their development and consumption of their products on a global, regional and national aspect. 
These problems concern both the internal differentiation that affects the development of the information and communication technologies themselves and the processes of their reproduction in the end users. Here stand out the problems related to nature, the way of reflecting the elements of the information and communication technologies in the processes of depreciation and their reproduction.

The need to clarify and regulate these processes at different levels is related to the specific character of the individual elements and the differentiated impact on them on the processes of physical, technological, commercial, programmed, and in aggregate, the moral obsolescence. These processes which can be efficiently and adequately managed through the implementation of a separate program related to them, which can become an integral part of the design, development, production and service in the operation of small and medium-sized enterprises with a production focus. Machines with $\mathrm{CNC}$, as a basic core of modern production are largely dependent on the aging of hardware and system software. The problems modern CNC industry faces are related to the need for smarter and more flexible solutions, enabling continuous improvement and upgrading of processes, through which to achieve an increased return of investments. The use of open architecture systems for managing these types of machines supports the ability to customize and make ongoing improvements in order to achieve optimal productivity. Of key importance here are also the technical applications of CAD / CAM / CAE technologies where, along with the improvement of technologies, there is a tendency for the introduction of new models and ways for granting licenses by suppliers. The development of information and communication technologies, the processes of reindustrialization and the formation of the structure of economy at national and global level, as well as the process of moral obsolescence that are not directly related, need to realize a synergistic effect in a direction of future development of small and mediumsized enterprises in order to increase their competitiveness.

\section{Information and Communication Technologies and the Problems of Restructuring Fixed Assets}

The economy of developed countries is characterized by a steady trend related to an increase in the relative share of services in gross domestic product and in parallel, and intangible assets. Major reasons for the growing influence of intangible assets in the economic life of the countries are determined by: the strong pressure of corporations to overcome the growing competition they face; the increasingly widespread penetration of information technologies and the emergence of such concept as the "knowledge economy", where the key point are the investments in knowledge and information (Spasova, 2011).

Intangible assets have a limited period of usefulness and this period can not exceed 20 years $^{1}$. An intangible asset may be considered to be of unlimited duration, when there is no limitation on the period during which that asset is expected to generate net cash receipts for the entity. Such an asset is not depreciated and its useful life is reviewed for

\footnotetext{
${ }^{1}$ International Accounting Standards (IAS) 38 - Intangible Assets
} 
each reporting period to confirm the circumstances that classify it as an intangible asset with an unlimited duration.

Determining the useful life of intangible assets depends on the possibilities for occurrence of risk events that can reduce the period during which they generate income for the enterprise.

Different methods may be used for this purpose, such as the standard (IAS 16 and IAS 38) not giving an advantage to a particular one and they are placed on the same board. The choice is based on the expected pattern of consumption, expected future economic benefits inherent in the asset, and is applied consistently in different periods, unless there is a change in the expected pattern of consumption of these future economic benefits. In this way, the depreciable amount of an asset is allocated on a systematic basis over its useful life. Methods of implementation include a number of approaches, among which the linear method, the declining balance method and the accelerated depreciation method. The application of the declining balance method is important in future expected decline in the prices of goods and services produced by assets. This decline may be an indication that the expected asset benefit will decrease on the basis of technical or economic aging (Bruseva 2013, Slade 2006).

Future economic benefits associated with an asset are realized by the enterprise mainly through its use. Other factors, such as technical and commercial obsolescence, while the asset is unused, often lead to a reduction in economic benefits that could be obtained from it. Therefore, when determining the useful life of the asset, all factors such as technical or commercial aging due to changes or improvements in production or due to a change in market demand for the product or service received from the asset need to be accounted for. The expected future sales price reductions of a good produced by the use of an asset could serve as a guideline for the expected technical or commercial aging of the asset, which in turn could reflect the reduction in future economic benefits inherent to the asset.

The development of ICT changes the structure and content of assets in a national and global perspective. This trend is changing under the influence of technical progress. ICT initially lead to an increase in the proportion of intangible assets within fixed assets. With the development of information services and in particular the cloud technologies in their varieties such as PaaS, SaaS, IaaS, etc., a new asset transformation becomes possible from tangible and intangible long-term to short-term assets that is, in running costs.

\section{Life-cycle and Programmed Obsolescence in ICT}

The main objective of the Product Lifecycle Management (PLM) system is to improve the efficiency of team interactions in the product development phase and the technical preparation for its production. This is aimed at achieving key competitive advantages by reducing the time for product marketing realization, reducing production costs, and enhancing product quality to protect value and price (Adizes 2004, Orr 2007). In addition, the product life-cycle management system must be tailored, analyzed and coordinated both at the level of development or improvement of the e-business system of organizations and economic entities (in the context of the intensive IT processes that have taken place over the last decades), and in the light of recent trends in the re- 
industrialization of ICT (to achieve a synergy effect and improvement of the competitive advantages in an environment marked by globalization and a high level of competition). The successful achievement of such complex business goals could be possible if the aggregate action of software and hardware to capture, centralize and manage processes and product data in electronic workflow is achieved. This also applies to the electronic management of projects, programs and resources in the development and introduction of new products. PLM and PDM (Product Data Management) solutions have both common and distinct features. In terms of basic functionality, both systems offer: storage of engineering data in a database; product structure maintenance; the generation of bills of materials (BOM); unlock / lock for editing in team work; process management and engineering change orders.

In addition to the standard features of PDM, PLM provides users with: support for models from multiple CAD systems in one assembled model; creating and managing company classifiers; management of project schedules, including tasks, deadlines and ongoing implementation; management of projects and programs when introducing new products into production; advanced management of product configurations, options and variants of the product; compliance management in accordance with user and regulatory requirements. Considering the rapid changes in technology, computer software and many other intangible assets are highly susceptible to technological obsolescence, which is why their useful life is often short. Moral, and in part the programmed obsolescence of the software is related to its life-cycle, and the phase of "end date of extended support". In this regard, it is necessary to note that often the management of organizations and economic entities, especially for SMEs that do not have specialized staff or specialists in the field of information services and support, do not properly or fully assess the specificity and synergy between system software such as operating systems and specialized software that is typically in the focus of designing or analyzing specific business or manufacturing processes. In a number of economic sectors, the need to intensify the processes of ICT re-industrialization as well as the interaction between the system and the specialized software is not properly taken into account. Regardless of the peak of quitting Windows XP and the transition to another operating system between 2012 and 2013 (Table 1), still in many sectors similar obsolete operating systems are functioning. This leads to potential breakthroughs in the information security of organizations and businesses that may lead to the loss of competitive advantage as a result of critical business information and know-how leaks, compromise of the production process and loss of reputation. Finally, it should be noted that organizations and businesses will increasingly have to take into account the life-cycle management policies of their products introduced by the software manufacturers themselves. For example, the specified Windows 10 data is consistent with a long-term customer support request and is strongly different from the standard operating conditions for the same product.

In recent years, manufacturers and their needs have changed significantly with regard to specialized application software. The two key information technologies - enterprise resource planning (ERP) and product lifecycle management (PLM) are imposed as critical factors for their market success (Peltonen 2000, Philpotts 1996). Both initiatives bring unique value to the enterprise, and when combined, ERP and PLM provide a 
complete collaborative environment that greatly influences the successful implementation of product development and the ability to maintain a competitive edge.

Table 1. Life-cycle of some client operating systems ${ }^{2}$

\begin{tabular}{|l|l|l|l|}
\hline $\begin{array}{l}\text { Client operating } \\
\text { systems }\end{array}$ & $\begin{array}{l}\text { Latest updates or service } \\
\text { pack }\end{array}$ & $\begin{array}{l}\text { Base Support } \\
\text { End Date }\end{array}$ & $\begin{array}{l}\text { End date of } \\
\text { long-term } \\
\text { support }\end{array}$ \\
\hline Windows XP & Service Pack 3 & 14 April 2009 г. & 8 April 2014 г. \\
\hline Windows Vista & Service Pack & 10 April 2012 г. & $\begin{array}{l}11 \text { April 2012 } \\
\text { г. }\end{array}$ \\
\hline Windows 7* & Service Pack & $\begin{array}{l}\text { 13 January 2015 } \\
\text { г. }\end{array}$ & $\begin{array}{l}14 \text { January } \\
2020 \text { г. }\end{array}$ \\
\hline Windows 8 & Windows 8.1 & 9 January 2018 г. & $\begin{array}{l}10 \text { January } \\
2023 \text { г. }\end{array}$ \\
\hline Windows 10 & $\begin{array}{l}\text { Windows 10 Enterprise } \\
\text { 2016 LTSB }\end{array}$ & 12 October 2021 & $\begin{array}{l}13 \text { October } \\
2026\end{array}$ \\
\hline
\end{tabular}

* Support for Windows 7 RTM without service packs ended on April 9, 2013.

For software products, there is practically no physical obsolescence, while programmed obsolescence is mainly associated with physical wear and tear and unfit for functioning and consumption. Planned obsolescence is a system of interrelated processes. Characteristic in this case is that their joint action gives rise to a synergistic effect, resulting in extremely short decommissioning periods. The current stage is characterized by an increasing number of methodologies, databases and tools aimed at forecasting, mitigating risk and managing the obsolescence of technologies. The summary of all the methodologies, databases and tools that are in use today, whether reactive, proactive or strategic, is that they focus primarily on in the hardware life-cycle (Sandborn, 2007).

\section{ICT in the Process of Re-Industrialization at Regional and National Level}

Reindustrialization characterizes the process of increasing the relative share of industry in the creation of gross new value within a national economy. The new hightech industrialization covers the expansion of the country's industrial base through the creation of new high-tech enterprises, as well as the revitalization of former industrial enterprises and industrial zones through recapitalization, technical and technological renewal. The combination of industrial and information technologies forming the Fourth Industrial Revolution or Industry 4.0 (Klaus, 2016) introduces a new economic policy that can be primarily industrial, although economic and industrial policy are not identical There are close interdependencies between the industry and the service sector. In industry there is a trend towards a strong consumer orientation as a result of individualized demand, which ultimately leads to a supply of increasingly new and complex individual products. Industrial goods contain an increasing relative share of services. The unbundling of these services out of production leads to an expansion of the service sector. In this way, more and more accompanying services are sold at the same time as the products are sold, which in practice means extension of the value chain.

${ }^{2}$ Microsoft Corporation, Annual Report, http://www.microsoft.com/investor/reports/ar12/index.html 
The reduction in the relative share of industry in gross domestic product is due not only to an increase in the relative share of the services sector but also due to deterioration in competitiveness. Characteristic of the new virtual technologies is the one-off investment and lower running costs, which are practically reduced to the depreciation of fixed assets. Each country, depending on the specific conditions and prerequisites, defines its policy of re-industrialization, which also depends on the level of deindustrialisation in its economy.

\section{ICT, CAD/CAM/CAE and CNC Systems in the Processes of Re- Industrialization}

The information technologies can be regarded as a key element of modern production structure and an important sector of any modern industry.

Computerized production consists of two basic elements: machine-computer, the main part of which is hardware and software providing which includes its most scientific core comprised of CAD/CAM/CAE/PDM/PLM systems. The core of the technology closely interacts within a single information space with the PDM (Product Data Management) system and is embedded in the PLM (Project Life Cycle Management) system environment as a product for life-cycle management technology (Figure 1).

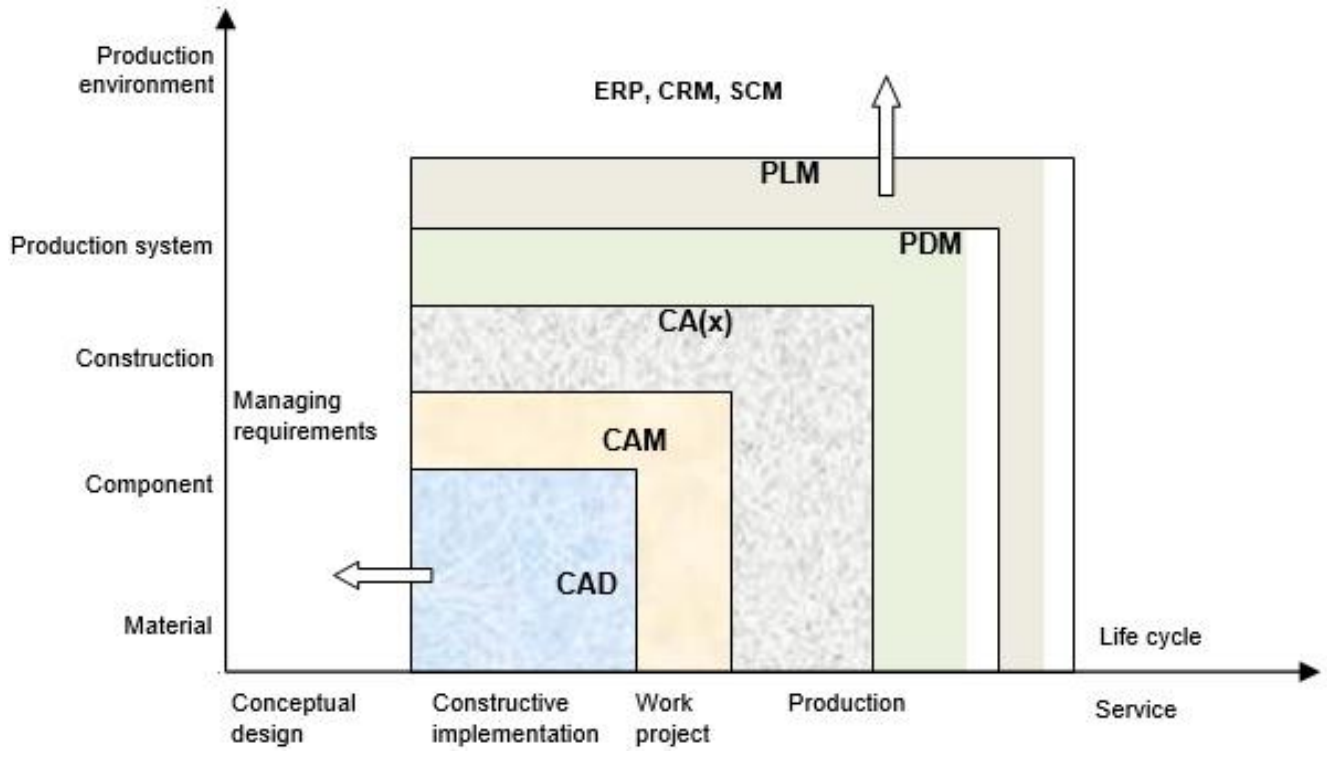

Figure.1. Structure of PLM system environment

The technologies for computer engineering as a set of CAD / CAM / CAE / PDM / PLM are constantly transformed and consolidated in accordance with the general trends in the development of the needs of the users, in the development of innovative products and in the utilization of new areas of applications (Lee, 1999). In accordance with the product life-cycle, CAD systems at the construction stage are used for geometric modeling (Ivanov, 2014), CAE systems for engineering calculations, and CAM systems for developing control programs for $\mathrm{CNC}$ machines at the production stage. 
The methods of development and implementation in the production of new products have undergone a significant change in recent years. CNC machines become a standard for modern automated machining equipment. The functionality of these machines is also the basis for the rapid development in the production of precision parts and the processing of complex contours and volumetric surfaces. This is the result of their increased computational power, new types of interpolation, the widespread use of increasingly sophisticated CAM systems, the development of accurate and fast-acting servo drives, the emergence of new components and materials for machine carrier systems, integration into the production of high-speed cutting tools, etc.

The ever-increasing competition in the various industries, is a major factor in the introduction of new CAD technologies, as well as the upgrading of those already used by small and medium-sized enterprises. This is determined by the requirement to produce more quality products in shorter periods in order to maintain existence and winning new customers. In addition, the need to accelerate the processes related to the launch of new products leads to the increasingly widespread use of CAE systems for modeling, product testing, analysis and simulation. Engineers and designers integrate sustainability in different ways in the process of their development, often focusing on different areas of the product's life-cycle. The first focuses on the development and production stage, looking for advantages associated with lower energy production and the appropriate choice of materials. The industrial design is aimed to stage "use associated with specific consumer desires and attitudes". The use of both directions - CAD and CAE greatly accentuates the end of the product's life cycle, whether the reusing or recycling practices are promoted, or to improve the systems for responsible product disposal. Integrating the benefits of their combined use leads to products that are more sustainable, while encouraging more sustainable behavior of consumers and producers (Lobos \& Babbitt, 2013). The use of specialized CNC machines leads to substantial changes or a complete change in production processes. The accuracy and the possibilities for elaboration of complex details are increased, while at the same time a number of technical and economic indicators of production are changed.

Modern $\mathrm{CNC}$ systems have high performance and high memory volumes, with extensive technology management capabilities with virtually unlimited complexity, high reliability and self-diagnosis functions. The CNC principle integrates multiple technology and transport equipment into automatic modules and flexible automated production systems which creates automatic plots, workshops and factories operating without or with a severe limitation of service staff.

\section{Conclusions and recommendations}

The modern processes in the development of the re-industrialization of economy are practically impossible without the application of modern information technology in the management of production systems. They change the structure, asset dynamics and intangible assets in particular, creating prerequisites for increasing the value added along the value chain. With the provided opportunities for new architecture of industrial systems, CAD / CAM / CAE and CNC technology, are fundamentally changing the traditional logic of production. Their gradual introduction, through the 
modernization of existing production capacities through the stepwise evolutionary development of existing enterprises, facilitates the transition from solid centralized production control to decentralized. Using them as a means supporting the processes associated with the planned risk management and obsolescence contributes to maximizing returns of investments in assets related to SMEs operating in the industry. They contribute to extending product life-cycles, reducing premature technological obsolescence by improving the use of materials.

The development of the two main directions of the information technologies, namely hardware and software, is reflected in the development of IT systems and their modification, which is a specific form of programmed and moral obsolescence. As a result of the development of information services and in particular cloud technologies, a reverse process of transformation of capital expenditures for tangible and intangible assets (hardware and software) into running costs is implemented. The physical durability of the software is practically unlimited - there is no physical extinction, which determines that the magnitude of the economic life of the asset will mainly depend on the moral obsolescence of hardware and software and, in particular, of the operating systems.

Reindustrialization at the various levels in the future will develop thanks to the high-tech industries representing the symbiosis of modern information and communication technologies and the development of intelligent CNC complexes. The existence of a specific obsolescence management policy based on the various evaluation methodologies is an important condition for achieving sustainable development and improving the competitiveness of businesses.

\section{References}

Adizes, I., (2004), Managing Corporate lifecycles, ISBN 0-937120-0-06-5

Bruseva M., (2013), The assessment of intangible assets - an element of the management of the innovation process in discreet production, Proceedings of 22-th conference "Automation of Discrete Production", vol.1 pp. 524 - 529. (in Bulgarian)

Ivanov R., (2014), Technological preparation of the manufacturing and development of control programs for mass production in the integrated "Protech" engineering automation system environment", $\mathrm{PhD}$ Thesis (in Bulgarian)

Klaus S., (2016), The Fourth Industrial revolution, ISBN 9781944835002

Lee, K., (1999), Principles of CAD/CAM/CAE Systems, Addison Wesley Longman inc., ISBN 0-13-178454-4

Lobos A. ,Callie W. Babbitt (2013), Integrating Emotional Attachment and Sustainability in Electronic Product Design, Challenges 2013, 4, pp.19-33; ISSN 2078-1547

Orr, J. (2007), PDM? PLM? What? http://www.machinedesign.com/archive/joel-orr-commentary-pdm-plm-what

Peltonen, H. (2000), Concepts and an Implementation for Product Data Management, PhD Thesis, ISBN 951-666-538-1.

Philpotts, M. (1996), An introduction to the concepts, benefits and terminology of product data management; Industrial Management \& Data Systems 96/4 [1996] 11-17, MCB University Press, ISSN 0263-5577

Sandborn P., (2007), Software Obsolescence - Complicating the Part and Technology Obsolescence Management Problem , IEEE Trans on Components and Packaging Technologies, Vol. 30, No. 4, pp. 886-888

Slade, G., (2006), Made to Break: Technology and Obsolescence in America, Harvard University Press, ISBN 9780674025721

Spasova R. (2011), Theory-applied problems of accounting for intangible assets, PhD thesis (in Bulgarian). 